\title{
ON THE RELATION BETWEEN COOLING RATE AND PART GEOMETRY IN POWDER BED FUSION ADDITIVE MANUFACTURING
}

\author{
*Nihat Yilmaz ${ }^{1, \text { a }}$, Mevlüt Yunus Kayacan ${ }^{1, b}$ \\ ${ }^{1}$ Suleyman Demirel University, Technology Faculty, Isparta, Turkey
}

\begin{abstract}
:
Direct metal laser sintering (DMLS), one of the laser powder bed additive manufacturing technologies produces solid metal parts from 3-D CAD data, layer by layer, by melting/sintering and bonding metal powders with a focused laser beam. In these processes isn't complete melting of powder particles in micro melt pools as well as selective laser melting (SLM) and electron beam melting (EBM). Thus some different stress conditions and defects occur depending on the temperature changes during manufacturing. In this study, this problem is investigated aspect cooling rate. Cooling rate affects the solidification process in the melting (sintering) process such as casting, welding, laser assisted processes. Therefore, it also affects part quality and properties. In the scope of study, it is tried to explain how occurring the internal stresses and distortions differ depending on the cooling rates of geometrically different parts in additive manufacturing. The residual stresses and deformations are analysed by FEA to see relation with geometry (volume, area) to cooling rate for Ti6Al4V materials. Cube shaped samples at 20, 40, 60, 80 and $100 \mathrm{~mm}$ edge dimensions have analysed by using FEA. Besides $10 \mathrm{~mm}$ cube sample is manufactured as solid and verified both as experimental and numerical. Based on the FEA results, cooling rate values are changed from 1.67 to 16.67 . In conclusion, the reasons of the problems occurring during laser powder bed fusion are investigated in terms of the cooling rate in relation with the samples geometry.
\end{abstract}

Keywords: additive manufacturing, powder bed fusion, cooling rate, Ti6Al4V, DMLS, residual stress

\section{Introduction}

The powder bed fusion (PBF) type additive manufacturing method allows the metal and polymer powders to be melt by means of an energy source. This process continues along the path of energy sources such as the preferred laser or electron beam. The machine that completes the first layer in this way completes the manufacturing by combining the other layers together. At the end of the production an entire part is obtained. PBF type additive manufacturing (AM) methods are generally known as SLM, DMLS and EBM [1-3].

There are various parameters that determine the properties (mechanical properties, dimensional accuracy etc.) of the parts manufactured by PBF AM. The parameters are generally caused by situations such as machine, powders and part design. At the beginning of these parameters are the machine parameters. Machine parameters can be specified as scan speed, laser power, scan distance, layer thickness, table preheat, laser focus diameter, scanning strategy and energy density. Depending on the machine parameters, mechanical properties changes after manufacturing, as well as part properties during manufacturing. The shrinkage, internal stress, residual stress, distortion and manufacturability of the parts also change [4-7].

*Corresponding author: Address: Faculty of Technology, Department of Mechanical and Manufacturing Enginering, Isparta Applied Science University, 32200, Isparta TURKEY. E-mail address: nihatyilmaz@sdu.edu.tr, Phone: +902462111569 
Furthermore, the manufacturability with PBF depends mainly on two situations. The first of these is the permanent distortion of the part. The other is the fact that permanent faults are caused by internal stresses on the part. Faults are commonly known as distortions, cracks and fractures. It can be said as a main reason that the internal stresses rise above the yield strength of the part. Residual stresses increase as the upper layers are added during manufacturing. The maximum stresses appear on the surface areas and a residual stress variation is observed depending on the scanning strategies. Residual stresses have been found to be very low in regions subjected to plastic deformation due to stress and expansion. As a result of deformation, it is assumed that the stressed regions are exposed to stress relaxation $[8,9]$.

When the studies in the literature are examined, it is found that the residual stress decreases as the scanning distance increases. Residual stresses at the center of the parts are minimum level. Distortion quantities show a parallel distribution to the residual stresses. Minimum residual stresses were obtained with grid and linear scanning strategies. By the spiral scanning, the maximum residual stresses were found. This can be attributed to the inward movement of the spiral scan. This is because when heat is applied from outside to inside, heat accumulation occurs in the part $[10,11]$. If the heat accumulation is excessive in the manufacture of lattice structured parts, the temperature may rise above the melting point and cause undesirable effects. For this reason, volumetric and dimensional deviations may occur. This is not the case only in lattice structures; it can be done for all geometries. It is a disadvantage that the lattice structured parts are mechanically weaker, but it is an advantage that the heat transfer is more and faster due to the large surface area. Thus, the amount of heat accumulated in the part does not exceed a certain point and the shrinkage conditions are limited $[12,13]$.

In addition to the machine parameters, design of parts are also very important on fault-free part production in additive manufacturing with PBF. The amount of accumulated and transferred heat depends on the part size and shape. Accordingly, the shrinkage behaviour will change. Because the internal stresses in the part are the result of the expansion and shrinkage behaviour. The residual stresses that occur as a result of physical events may not be completely eliminated during the manufacturing of parts. In this case, residual stresses are formed [14]. A term explaining this situation emerges as a cooling rate. The cooling rate describes the timedependent behaviour during the cooling down of the part to room conditions for the manufacturing processes that occur at high temperatures. The concept of cooling rate was first used in the casting method. It is an approach that has a key designation, especially in the design of the feeders. It is expected that the feeders in the cast will cool later than the mold cavity. Thus, feeders will be able to eliminate the shrinkage during cooling. Subsequently, this approach has begun to emerge as an unstable temperature distribution, such as welding and laser-assisted manufacturing methods, and in processes involving difficult-to-control thermal movements. Afterward, this approach has been adapted both for unbalanced temperature distribution such as welding and laser-assisted manufacturing methods, and for processes involving hard-to-control thermal movements. It is a term used to estimate the internal structure of the weld depending on the cooling rate in the welding method [15].

Cooling rate is affected by geometry, material properties, manufacturing conditions and environment. As a consequence of associating the temperature and residual stress measurements with the cooling rate, it should be considered whether or not it is a valid approach in additive manufacturing. The cooling rate is expressed as the volume divided by 
the surface area. It is indicated at equation $1 . C_{R}$ is cooling rate, $\mathrm{V}$ is volume of part and $A_{S}$ is heat transferred surface area [16].

$C_{R}=V / A_{S}$

The cooling rate approach is very important in order to understand the basis of many problems that come to the foreground. In Equation 1, part of the Chvorinov's rule is showed. Chvorinov's rule is a method for calculating the period of cooling [17]. It is not possible to use it directly in PBF methods but it is thought to be a useful method if it is developed. By evaluating the cooling ratio, the residual stresses and distortions together, it will be possible to avoid the mistakes that occur during manufacturing. In this study, the effect of cooling rate on part properties was investigated depending on the part geometry with PBF additive manufacturing.

\section{Material and Method}

EOS M280 DMLS (Direct Metal Laser Sintering) machine has been analyzed for failure in manufacturing parts. The table size is $280 * 280 * 20 \mathrm{~mm}$. The laser power is $190 \mathrm{~W}$, the scanning speed is $900 \mathrm{~mm} / \mathrm{s}$, the scanning distance is $0.09 \mathrm{~mm}$, the laser focus diameter is 0.15 $\mathrm{mm}$, the layer thickness is $0.03 \mathrm{~mm}$. The energy density was calculated as $78.19 \mathrm{~J} / \mathrm{mm}^{3}$. The material is Ti6A14V titanium alloy.

The inherent strain values required for distortion and residual stress calculations to be made with the Simufact Additive program; $\varepsilon_{x}=-0,00581473, \varepsilon_{y}=-0,0026075, \varepsilon_{z}=-0,0242824$. $1 \mathrm{~mm}$ size tetragonal mesh types are preferred for mesh processing.

The study first started with a comparison of the actual results with the results obtained from the software. Thus, the error margin of the software is presented for the study. $10 * 10 * 10$ mm samples were manufactured for comparison and residual stress measurement was carried out. Subsequently, analyses were performed for the main experiments $(20,40,60,80$ and 100 mm-edged cubes). The analysis results were examined in terms of distortion and residual stresses. In addition, the relationship between parts geometry and the cooling rates of the parts has been tried to be evaluated. Sample designs and cooling rate characteristics are shown in Table 1.

Table 1. Sample Properties

\begin{tabular}{ccccc}
\hline $\begin{array}{c}\text { Sample } \\
\text { number }\end{array}$ & Edge dimensions & Volume & Surface area & Cooling rate \\
\hline 1 & 10 & 1000 & 600 & 1,67 \\
2 & 20 & 8000 & 2400 & 3,33 \\
3 & 40 & 64000 & 9600 & 6,67 \\
4 & 60 & 216000 & 21600 & 10,00 \\
5 & 80 & 512000 & 38400 & 13,33 \\
6 & 100 & 1000000 & 60000 & 16,67 \\
\hline
\end{tabular}




\section{Results and Discussions}

First, the simulation and real results of a $10 * 10 * 10 \mathrm{~mm}$ samples were compared and the accuracy of the simulations was determined as \%error. Residual stresses were measured from the upper surface of the part after manufacturing with XRD test. Measurements were made on a Bruker instrument and results were obtained according to Pearson VII method. The average maximum stress value was obtained as $330 \mathrm{MPa}$ at the measurements. As a result of finite element analysis, the amount of residual stresses was found to be $270 \mathrm{MPa}$ for the same point. By comparing the two cases, it can be said that results are achieved with $18 \%$ error.

After the definition of error rates for the analyses, the manufacturing simulations of the samples as shown in Figure 1 were carried out. Manufacturing simulations were completed by producing all parts on the same table. In the simulations, residual stresses, distortions on the $\mathrm{z}$ axis and the total distortion data are considered. Figure 1 and Figure 2 show the results of the analysis.

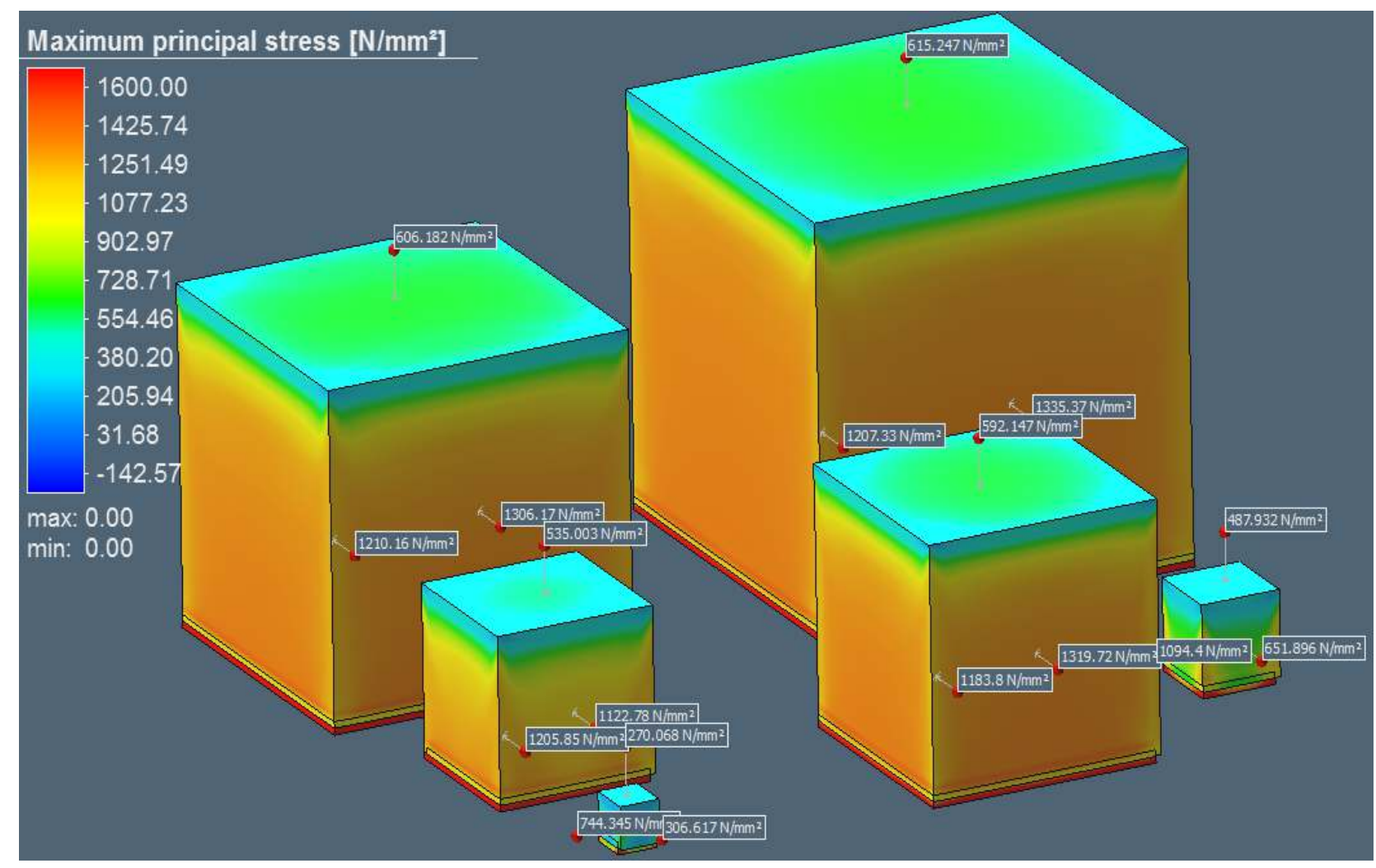

Figure 1. Residual stresses after manufacturing parts 


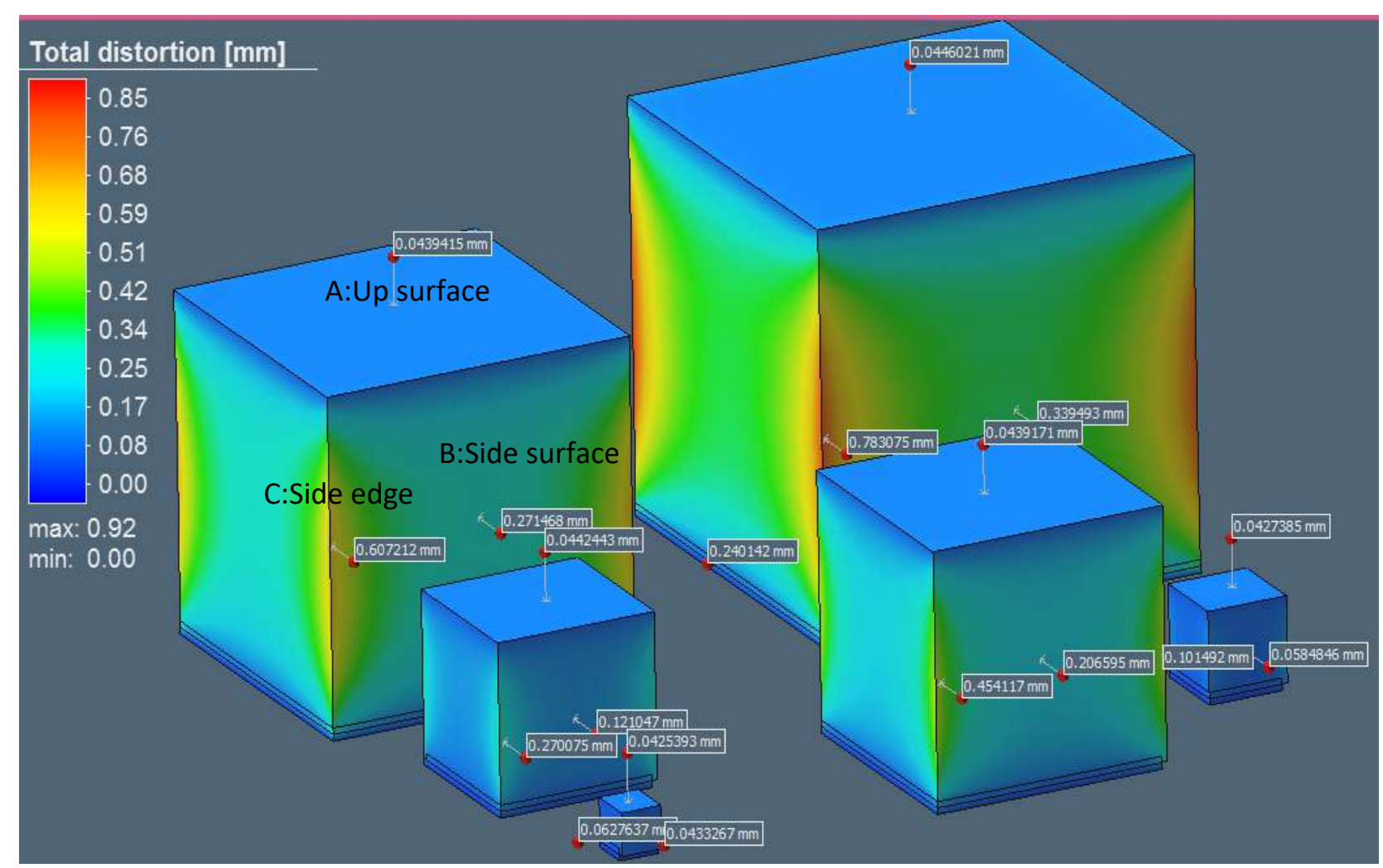

Figure 2. Amount of distortion occurring after manufacturing

As the part dimensions increases, the amount of residual stress increases, but when the cooling rate exceeds $10 \mathrm{~mm}$, the stresses remain constant at a certain value. Maximum stresses occur on the side surface and edges of the part. Where the cooling rate is less than $10 \mathrm{~mm}$, the stresses at the edges are higher, while the cooling rate is greater than $10 \mathrm{~mm}$, the stresses have reached higher on the side surfaces. The stresses on the side surfaces of the parts with a cooling rate greater than $10 \mathrm{~mm}$ exceed the yield strength of the Ti6Al4V material. For this reason, there is a high failure probability such as cracks. Residual stress amounts depend on cooling rates are shown in figure 3. 


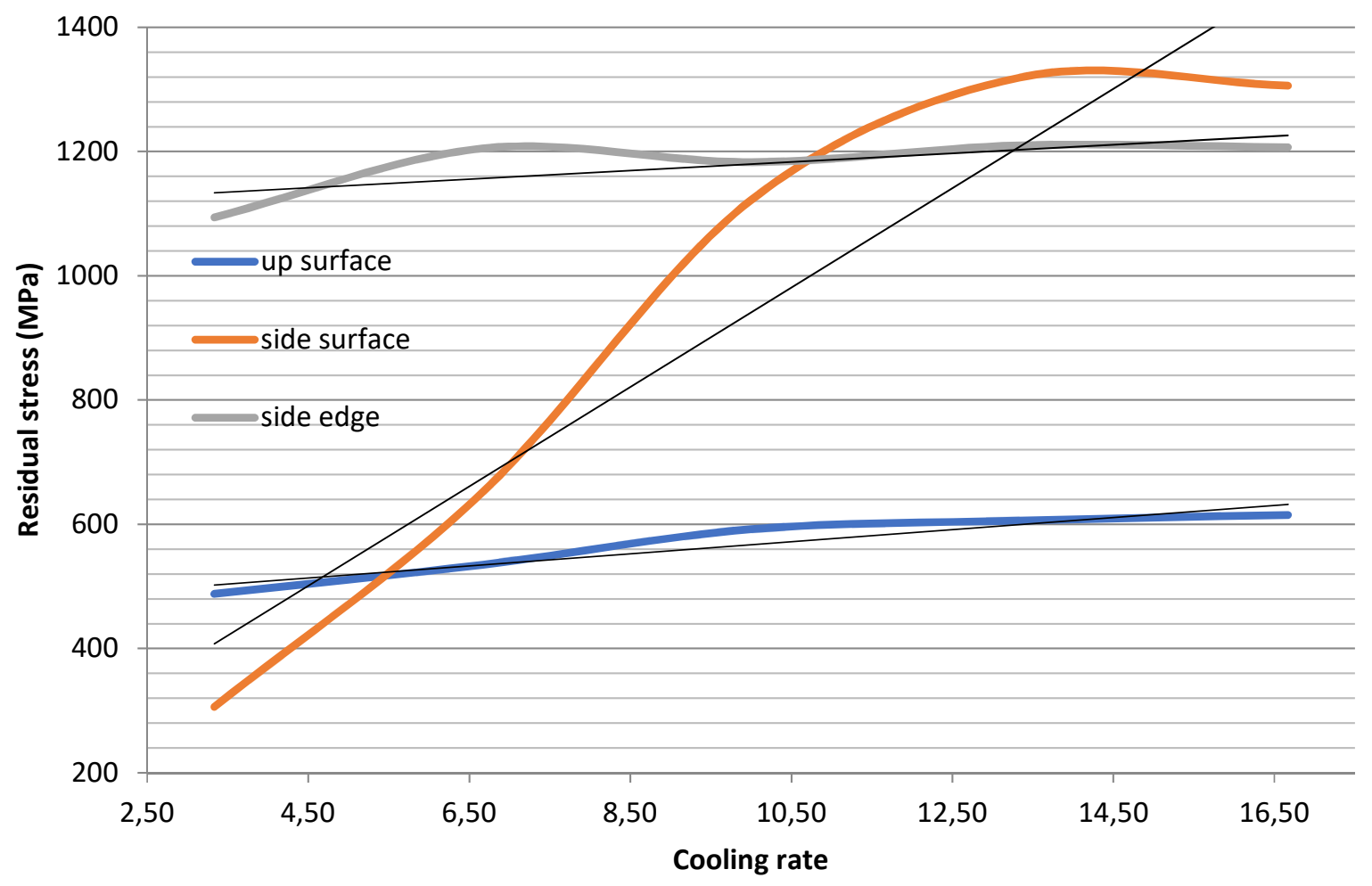

Figure 3. Residual stresses depends on the cooling rates

The cooling rate-residual stress equations produced by the curve fitting method with the support of figure 3 are also calculated. The equation obtained for the up surface is:

Residual Stress $=9,75^{*}$ cooling rate $+469,7$

The equation obtained for the side surface is:

Residual Stress $=80,01 *$ cooling rate $+140,9$

The equation obtained for the side edge is:

Residual Stress $=6,93 *$ cooling rate $+1110,5$

The accuracy of equations 2 and 4 is much higher than that of equation 3 . Because the curves can be placed by a very harmonious way.

In the same way, the analysis results are evaluated in terms of distortion amounts. Distortion values were examined in terms of both total distortion and distortion along the z-axis. According to the results, as the part size increases, the cooling module increases and the distortion also increases. The amount of deformation is related to the part size. The maximum distortions occur on the side edges. For this reason, the critical region is the side edges. Errors will first occur in these regions. In terms of distortion in the $\mathrm{Z}$ axis; it can be formulated as a distortion that forms on the up surface and side edges. However, the distortion on the side 
surface varies independently of the cooling rate. Distortions showed a linear decrease to the cooling rate of $10 \mathrm{~mm}$ and increased afterwards.

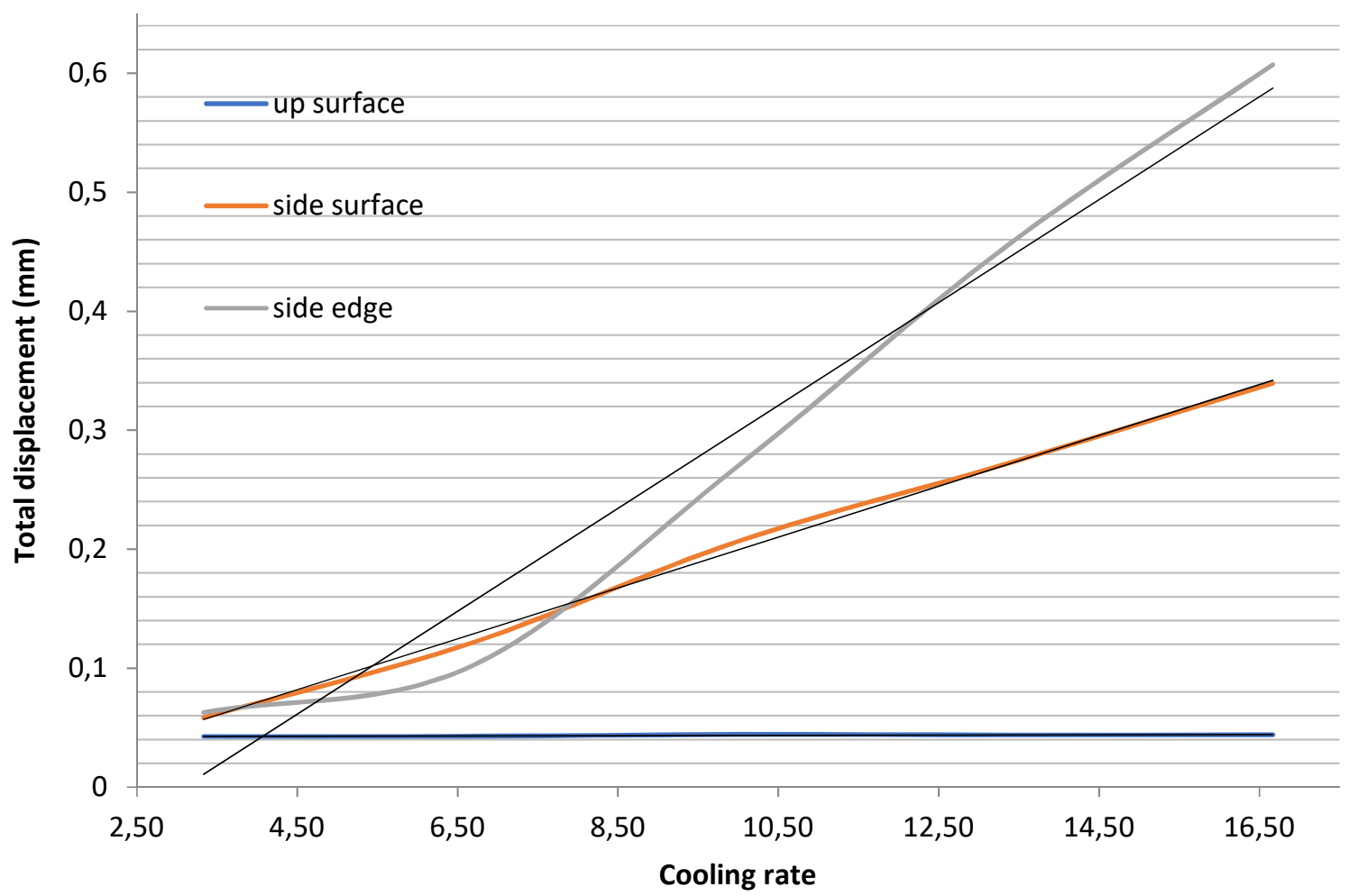

Figure 4. Total distortions depends on cooling rates

The cooling rate/total distortion equations produced by the curve fitting method with the aid of figure 4 are also calculated. The equation obtained for the top surface is:

Total displacement $=0,0001 *$ cooling rate $-0,0423$

The equation obtained for the side surface is:

Total displacement $=0,0214^{*}$ cooling rate $-0,143$

The equation obtained for the side edge is:

Total displacement $=0,0432 *$ cooling rate $-0,1333$

As a result of the investigations, stress and distortion conditions, in which the cooling rate is directly related, were determined. However, when looking at the distortion and residual stresses at the side edges, it seems that it is not related to the cooling rates.

\section{Conclusion}

Distortions and residual stresses, which cause failures during powder bed fusion additive manufacturing, were analysed. Interpretation of the analysis gave the following results: 
- As the part size increases, the cooling rates of the parts increase, which increases the amount of residual stress and distortion that occurs in the part. However, it is not possible to determine the defects on the side surfaces only by examining the cooling rate.

- Residual stresses are high at some points of the parts and distortion values are high at some other points. The amount of residual stress is higher on the side surfaces of the part and the distortion values are higher in the edge regions. As a result, the distortion that occurs at the edges of the part triggers the mechanism called stress relaxation.

- The maximum stresses have formed on the surfaces of the parts. For this reason, faults are expected to appear on the surfaces.

- If the cooling rate increases, the possibility of error in the part increases. For this reason, the cooling rate of the part should be tried to be reduced. With this target; the surface area should be increased while the volume is reduced. This is most easily accomplished by placing the lattice systems on the part. It is understood that failures can be reduced by designing the surface areas in this way. In addition, by using lattice structures in parts where strength is not desired, both parts can be lightened and the cooling rate can be reduced.

In future work, real experiments and simulations can be made on parts designed with different cooling rates in the same sized parts (volume and outer geometry). The cooling rate formula can be specially developed for additive manufacturing. Particularly in the additive manufacturing process the time-dependent variation of the cooling rate can be formulated because parts produced layer by layer.

\section{Acknowledgements}

Authors are thankful to Netform and MSC Software Company for granting trial licence for "Simufact Additive".

\section{References}

[1] Everton SK, Hirsch M, Stravroulakis P, Leach RK, Clare AT. Review of in-situ process monitoring and in-situ metrology for metal additive manufacturing. Mater. Des. 2016; 95, 431-445.

[2] Frazier WE. Metal additive manufacturing: A review. J. Mater. Eng. Perform. 2014; c. 23, 6, 1917-1928.

[3] Kayacan MY, Sayer S. Ürün geliştirme sürecinde hızlı prototip uygulamaları. Plast. Derg. 2014; 125, 122-130.

[4] Paul, R. (). Modelling and Optimization of Powder Based Additive Manufacturing (AM) Processes. (Electronic Thesis or Dissertation). Retrieved from https://etd.ohiolink.edu/

[5] Xie F, He X, Cao S, Qu X, Structural and mechanical characteristics of porous 316L 
stainless steel fabricated by indirect selective laser sintering. J. Mater. Process. Technol. 2013 ; c. $213,6,838-843$.

[6] Ning Y. Process Parameter Optimization for Direct Metal Laser Sintering ( DMLS ). (Electronic Thesis or Dissertation). Retrieved from https://core.ac.uk/download/pdf/48628004.pdf

[7] Ningy Y, Fuhy JYH, Wongy YS, Lohy HT. An intelligent parameter selection system for the direct metal laser sintering process. Int. J. Prod. Res 2004; c. 42, 1, 183-199.

[8] Dunbar AJ, Denlinger ER, Gouge MF, Simpson TW, Michaleris P. Comparisons of laser powder bed fusion additive manufacturing builds through experimental in situ distortion and temperature measurements. Addit. Manuf. 2017; 15, 57-65.

[9] Keller T, Lindwall G, Ghosh S, Ma L, Lane BM, Zhang F, Kattner UR, Lass EA, Heigel JC, Idell Y, Williams ME, Allen AJ, Guyer JE, Levine LE. Application of finite element, phase-field, and CALPHAD-based methods to additive manufacturing of Ni-based superalloys. Acta Mater. 2017; c. 139, 244-253.

[10] Simchi A, Pohl H. Effects of laser sintering processing parameters on the microstructure and densification of iron powder. Mater. Sci. Eng. A 2003; c. 359, 1-2, 119-128.

[11] H. Pohl, A. Simchi, M. Issa, ve H. C. Dias, "Thermal stresses in direct metal laser sintering”, Proc. SFF Symp., 366-372, 2001.

[12] Yan C, Hao L, Hussein A, Young P, Huang J, Zhu . Microstructure and mechanical properties of aluminium alloy cellular lattice structures manufactured by direct metal laser sintering. Mater. Sci. Eng. A 2015; c. 628, 238-246.

[13] Criales LE, Arısoy YM, Lane B, Moylan S, Donmez A, Özel Ö. Predictive modeling and optimization of multi-track processing for laser powder bed fusion of nickel alloy 625. Addit. Manuf. 2017; c. 13, ss., 14-36.

[14] Matveeva M.O. Effect of Chromium and Titanium on Structure and Properties of White Cast Iron. Metallurgical and Mining Industry 2013; Vol. 2, No. 1.

[15] Di X, Ji S, Cheng F, Wang D, Cao J. Effect Of Cooling Rate On Microstructure, İnclusions And Mechanical Properties Of Weld Metal İn Simulated Local Dry Underwater Welding. Materials and Design 2015; 88, 505-513.

[16] Sorel Metal, "Ductıle Iron The essentials of gating and risering system design", Rio Tinto Iron \& Titanium Inc. 2000, 22-24, Rio.

[17] Jelínek P, Elbel T. Chvorinov's rule and determination of coefficient of heat accumulation of moulds with non-quartz base sands. Archives of Foundry Engineering $2000 ; 10 / 4,77-82$. 